\title{
Advances in understanding and treating ADHD
}

\author{
Kevin M Antshel', Teresa M Hargrave, Mihai Simonescu, Prashant Kaul, Kaitlin Hendricks and Stephen V Faraone
}

\begin{abstract}
Attention deficit hyperactivity disorder (ADHD) is a neurocognitive behavioral developmental disorder most commonly seen in childhood and adolescence, which often extends to the adult years. Relative to a decade ago, there has been extensive research into understanding the factors underlying ADHD, leading to far more treatment options available for both adolescents and adults with this disorder. Novel stimulant formulations have made it possible to tailor treatment to the duration of efficacy required by patients, and to help mitigate the potential for abuse, misuse and diversion. Several new non-stimulant options have also emerged in the past few years. Among these, cognitive behavioral interventions have proven popular in the treatment of adult ADHD, especially within the adult population who cannot or will not use medications, along with the many medication-treated patients who continue to show residual disability.
\end{abstract}

\section{Introduction}

Attention deficit hyperactivity disorder (ADHD) is a neurobehavioral disorder that is defined by persistent and maladaptive symptoms of hyperactivity/impulsivity and inattention [1] (please see Table 1 for diagnostic criteria). People with ADHD often have serious impairments in academic, social and interpersonal functioning. ADHD is also associated with several comorbid conditions and disorders such as mood disorders, disruptive behavior disorders and learning disabilities. This review will review current conceptualizations of the causes of ADHD and advances in treatment, including discussions of stimulant and non-stimulant medication and cognitive behavioral therapy (CBT).

\footnotetext{
* Correspondence: antshelk@upstate.edu

State University of New York, Upstate Medical University, Department of Psychiatry and Behavioral Sciences, 750 East Adams Street, Syracuse, NY 13210, USA
}

(c) 2011 Antshel et al; licensee BioMed Central Ltd. This is an Open Access article distributed under the terms of the Creative Commons Attribution License (http://creativecommons.org/licenses/by/2.0), which permits unrestricted use, distribution, and reproduction in any medium, provided the original work is properly cited.

\section{Understanding ADHD}

The ADHD prevalence was once estimated to be 3 to $5 \%$ of school-age children [1], but more recent studies place the figure closer to 7 to $8 \%$ of school-age children [2] and 4 to $5 \%$ of adults [3]. Prevalence clearly varies, with risk factors including age, male gender, chronic health problems, family dysfunction, low socioeconomic status, presence of a developmental impairment and urban living [4]. The disorder is found in all countries surveyed, with rates similar to, if not higher than, those found in North America [5,6]. Differences across ethnic groups within North America are sometimes found, but seem to be more a function of social class than ethnicity [7]. Although diagnosed as a categorical disorder, ADHD may actually represent the extreme end of a normal continuum for the traits of attention, inhibition and the regulation of motor activity [8].

Current advances in cognitive neuroscience, neuroimaging, and behavioral and molecular genetics have provided evidence that ADHD is a complex neurobiological disorder. Many regions of the brain and several neurotransmitters have been implicated in ADHD. Biologically, the neurotransmitter dopamine has received considerable attention as being relevant to understanding ADHD. Neurologically, the prefrontal cortex seems to be relevant to understanding ADHD. The prefrontal cortex has a high requirement for dopamine, and plays a role in cognitive functions such as executive functions. The prefrontal cortex has many reciprocal connections with other brain regions, including the striatum (caudate nucleus, putamen), cerebellum and parietal cortex. Research has indicated that some of these brain regions are slightly smaller or have decreased activation in people with ADHD.

\section{Comorbid conditions}

Pediatric ADHD commonly co-occurs with multiple psychiatric disorders including mood, anxiety and disruptive behavioral disorders $[9,10]$. Likewise, adult ADHD is also associated with diagnoses of comorbid mood, anxiety and substance-use disorder [11-17]. Comorbidity rates in adult ADHD do not differ as a function of gender [18]. ADHD in adults is not always

\section{Biomed Central}




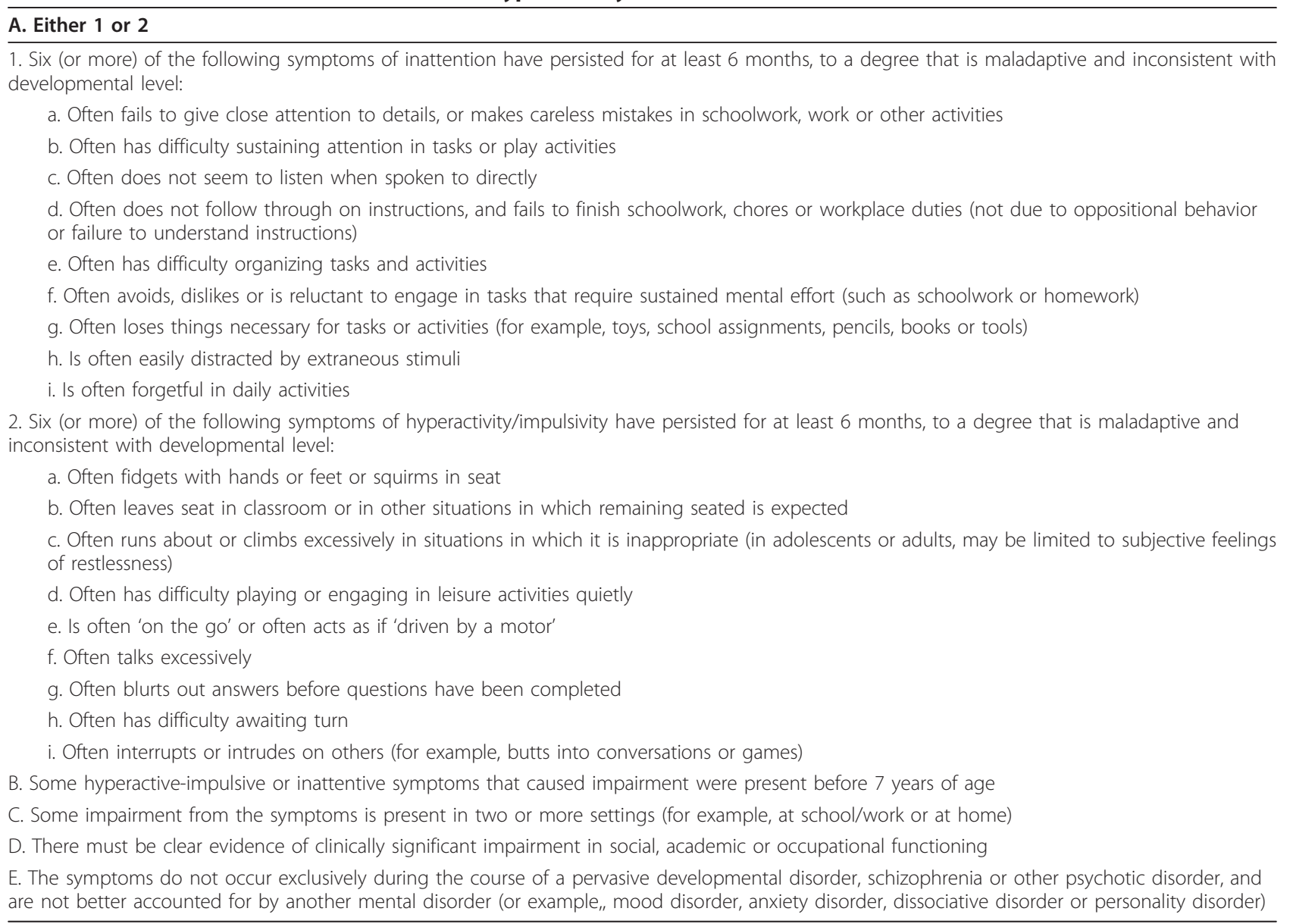

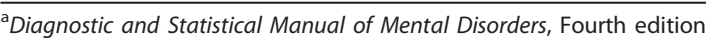

comorbid with other concurrent psychiatric conditions, and some data suggest that 'uncomplicated' ADHD exists in about 20 to $25 \%$ of adults with ADHD [13].

\section{Current research}

Research on ADH) has been published at an exponential rate during the past 30 years [19]. Within the past 3 years (2008 onwards), theories about the etiology of ADHD and therapies for it have evolved concurrently [20-23]. Psychopharmacological agents affecting catecholaminergic and $\alpha$-2-adrenergic transmission continue to figure prominently in ADHD treatment [24,25]. Over the past 3 years, however, more attention has been paid to prescribing patterns [26-28], matching medication with patient characteristics [29], and factors that promote treatment adherence in pediatric [30-35] and young adult populations [36]. In the following section, current treatment options for both adults and children with ADHD will be discussed.

\section{ADHD treatments}

There are both pharmacological and non-pharmacological treatments for ADHD for both children and adults. Pharmacological approaches to treatment are the most common, and typically consist of stimulant medication, such as methylphenidate, dexmethylphenidate, mixed amphetamine salts and lisdexamfetamine dimesylate (LDX). However, non-stimulants such as atomoxetine, clonidine and guanfacine have also been found to be efficacious in treating ADHD. In addition to medication, there are also non-pharmacological treatments. Many of the drugs discussed in this section are currently licensed for use in North America, but not in other countries.

Treatment for children with ADHD includes parent and teacher training in effective behavior-management techniques aimed at reducing the problem behaviors associated with ADHD. CBT is a skill-based approach commonly used for adults with ADHD and there are some preliminary data showing its efficacy. 


\section{Stimulants}

For most patients with ADHD, stimulants remain the first choice for medication management, as meta-analyses of existing research have shown that they are more efficacious than non-stimulant medications [37]. Various delivery mechanisms exist. Physicians may choose from a number of delivery mechanisms for these stimulants (liquid, sprinkle, tablet, capsule or patch); from active isomer, mixtures of active and less active isomers, or pro-drug; from and immediate-release, intermediaterelease or extended-release formulations [38]. For both the methylphenidate and amphetamine families, there are arrays of choices, which enable practitioners to better tailor the duration of medication efficacy throughout the day to the needs of the individual (please see Table 2 for descriptions of stimulant options).

Research has continued to suggest that osmoticrelease oral system (OROS) methylphenidate lessens ADHD symptoms throughout the day and has greater adherence, thought to be associated with the convenience of once-daily dosing [39-41]. Dexmethylphenidate extended-release (XR) and transdermal methylphenidate also offer this benefit. Dexmethylphenidate comes in capsules that can be opened and mixed with food, and has the earliest onset of efficacy of the long-acting preparations $[42,43]$. Transdermal methylphenidate bypasses the oral route entirely, and in short-term studies is associated with efficacy throughout the day, with improved family quality of life, and when carefully titrated, little effect on sleep [44-46]. Greater absorption of medication occurs when the patch is applied to the buttocks rather than to the subscapular area [47].

Comorbid anxiety was not found to affect stimulant efficacy in a recent study [48], and some studies suggest that treatment with stimulants can help to lessen the likelihood of other psychiatric comorbidities during adolescence [49], including cigarette use and substance abuse [50]. However, meta-analyses of stimulants and other ADHD medications in the treatment of ADHD comorbid with tic disorders concluded that supratherapeutic doses of dextroamphetamine should be avoided in this population. These studies also indicated that methylphenidate gave the best control for ADHD and that $\alpha$-2-agonists produced the best improvement in both tics and ADHD [51,52].

The commonest side-effects of stimulants (decreased appetite, trouble with sleep onset) have also continued to receive recent research interest. Some research suggests that it is difficult to predict which children with ADHD will have adverse effects, based upon demographic and clinical characteristics [53]. Although rare, serious cardiovascular side-effects have been identified with stimulant use [54]; however, the common effects on blood pressure, heart rate and exercise parameters are usually of no clinical significance [55-57]. Consensus has been reached in the USA, Canada and Europe that routine electrocardiography screening and/or cardiology investigations are needed before starting stimulant use only in those with a positive family or personal cardiac history [58,59]. Likewise, no cytogenetic side-effects from stimulant use have been reported [60,61]. However, a recent review article has shown that treatment with stimulants in childhood modestly reduced expected height and weight [62]. These effects were dose-dependent and attenuated over time. The general consensus on cardiovascular side-effects at this point is that the short/medium term side-effects are usually of no clinical significance, but the long-term potential side-effects are less certain [63].

Within the past 3 years, concerns have continued to rise regarding the abuse of stimulants and/or drug diversion [64-66]. Some have suggested that in ADHD patients with conduct disorder or comorbid substance abuse, psychostimulants should be used with caution [67]. Long-acting stimulants are less prone to diversion, probably because extraction of active drug is more difficult, and for some, the delivery of drug to the brain is slower. The new stimulant pro-drug LDX offers some protection from these problems. LDX requires gut metabolism to reach its active form, and hence lessens the likelihood of abuse and overdose. The efficacy and sideeffects of LDX are similar to the other long-acting stimulant preparations [68-72].

In summary, stimulant medication is often the first choice for medication management of ADHD. Research has shown that stimulant medication is an effective treatment for many of the symptoms associated with ADHD. However, there are some concerns about diversion of these medications for misuse and abuse, and some rare but serious cardiovascular side-effects can occur with the use of stimulant medication. In addition to stimulant medication, some non-stimulant medication has been shown to be efficacious for the treatment of ADHD (Table 2).

\section{Non-stimulants}

Some children may not respond to stimulant medications, or may not be able to tolerate the stimulant medications due to side-effects (for example,, loss of appetite). Thus, several non-stimulant medications are also used for ADHD pharmacotherapy. Modafinil [73] and reboxetine [74,75] have both shown some promise in the treatment of ADHD. Drugs approved by the US Food and Drug Administration (FDA) for the treatment of ADHD include the selective norepinephrine reuptake inhibitor (SNRI), atomoxetine, a long-acting form of guanfacine, and a long-acting form of clonidine (Table 2). Clonidine and guanfacine have also been approved 
Table 2 Current pharmacological treatments approved for attention deficit hyperactivity disorder (ADHD)

\begin{tabular}{|c|c|c|c|c|c|}
\hline Class & $\begin{array}{l}\text { Generic name, formulation } \\
\text { and brand name }\end{array}$ & Daily dosage & Duration & Mechanism of action & Common Side-effects \\
\hline & & STIMULANTS & & & \\
\hline \multirow[t]{3}{*}{ Methylphenidate } & $\begin{array}{l}\text { Immediate-release/short-acting } \\
\text { (Ritalin, Methylin, Desoxyn) }\end{array}$ & $\begin{array}{l}\text { Initial 5-18 mg; increase as needed until beneficial } \\
\text { effects peak or unacceptable side effects develop } \\
\text { Two to three times daily; can titrate as needed as long } \\
\text { as beneficial effects are greater than side effects }\end{array}$ & $\begin{array}{l}3 \text { to } 6 \\
\text { hours }\end{array}$ & $\begin{array}{l}\text { Blocks reuptake of D, } \\
\mathrm{N} \\
\text { Release of D from } \\
\text { storage vesicles }\end{array}$ & $\begin{array}{l}\text { Appetite suppression, delay of sleep onset, } \\
\text { abdominal pain, headache, rebound irritability, } \\
\text { tics (motor, vocal), jitteriness }\end{array}$ \\
\hline & $\begin{array}{l}\text { Intermediate-acting (Metadate } \\
\text { ER, Metadate CD, Methyllin ER, } \\
\text { Ritalin LA, Ritalin SR) }\end{array}$ & One to two times daily & $\begin{array}{l}3 \text { to } 8 \\
\text { hours }\end{array}$ & Same & Same \\
\hline & $\begin{array}{l}\text { Extended release/long-acting } \\
\text { (Concerta, Daytrana Patch) }\end{array}$ & Once daily (Patch left on for 9 hrs) & $\begin{array}{l}8 \text { to } 12 \\
\text { hours }\end{array}$ & Same & Same \\
\hline \multirow[t]{2}{*}{ Dexmethylphenidate } & Short-acting (Focalin) & Two to three times daily; initial half that of IR MPH & $\begin{array}{l}4 \text { to } 5 \\
\text { hours }\end{array}$ & Same & Same \\
\hline & $\begin{array}{l}\text { Extended-release/long-acting } \\
\text { (Focalin XR) }\end{array}$ & Once daily & $\begin{array}{l}8 \text { to } 12 \\
\text { hours }\end{array}$ & Same & Same \\
\hline \multirow[t]{3}{*}{ Amphetamines } & $\begin{array}{l}\text { Immediate-release/short-acting } \\
\text { (Dexedrine, DextroStat, Adderall) }\end{array}$ & Initial dose half IR MPH; two to three times daily & $\begin{array}{l}4 \text { to } 6 \\
\text { hours }\end{array}$ & $\begin{array}{l}\text { Release of D newly } \\
\text { synthesized D; blocks } \\
\text { reuptake of D, N }\end{array}$ & Same \\
\hline & $\begin{array}{l}\text { Intermediate-acting (Dexedrine } \\
\text { spansule) }\end{array}$ & One to two times daily & $\begin{array}{l}6 \text { to } 10 \\
\text { hours }\end{array}$ & Same & Same \\
\hline & $\begin{array}{c}\text { Extended-release/long-acting } \\
\text { (Adderall-XR) }\end{array}$ & Once daily & $\begin{array}{l}8 \text { to } 12 \\
\text { hours }\end{array}$ & Same & Same \\
\hline $\begin{array}{c}\text { Prodrug } \\
\text { Amphetamines }\end{array}$ & Lisdexamfetamine (Vyvanse) & Initial $4 \times \mathrm{IR}$ MPH once daily & $\begin{array}{l}8 \text { to } 12 \\
\text { hours }\end{array}$ & Same & Same \\
\hline
\end{tabular}


Table 2 Current pharmacological treatments approved for attention deficit hyperactivity disorder (ADHD) (Continued)

\begin{tabular}{|c|c|c|c|c|c|}
\hline & & NON - STIMULANTS & & & \\
\hline \multirow[t]{2}{*}{ NRI } & Atomoxetine (Strattera) & $\begin{array}{c}\text { Initial } 0.5 \mathrm{mg} / \mathrm{Kg} \text {; Increase to } 1.2-1.8 \mathrm{mg} / \mathrm{Kg} \text { one to } 2 \\
\text { times a day }\end{array}$ & $\begin{array}{l}18 \text { to } 24 \\
\text { hours }\end{array}$ & $\begin{array}{l}\text { Blocks } N \text { reuptake at } \\
\text { synapse }\end{array}$ & $\begin{array}{l}\text { Sedation, Gl irritability, palpitations, sweating, } \\
\text { increased suicidal thoughts }\end{array}$ \\
\hline & & ALPHA2 AGONISTS & & & \\
\hline \multirow[t]{3}{*}{ Clonidine } & IR Clonidine (Catapres) & $\begin{array}{l}\text { Initial dose } 0.05-0.1 \mathrm{mg} \text { at night; titrate to max } 0.4 \mathrm{mg} / \\
\text { per day }\end{array}$ & $\begin{array}{l}3 \text { to } 6 \\
\text { hours }\end{array}$ & $\begin{array}{l}\text { Arousal at locus } \\
\text { ceruleus by N } \\
\text { inhibition }\end{array}$ & $\begin{array}{l}\text { Sedation, Low blood pressure, rebound } \\
\text { hypertension }\end{array}$ \\
\hline & ER Clonidine (Kapvay) & Initial $0.1 \mathrm{mg}$ qhs; titrate to $\max 0.4 \mathrm{mg}$ qhs; once daily & $\begin{array}{l}12 \text { to } 24 \\
\text { hours }\end{array}$ & Same & Same \\
\hline & Clonidine patch (catapres TDS) & Initial TTS-1 up to TTS-3 & $\begin{array}{l}1 \text { to } 5 \\
\text { days }\end{array}$ & Same & Same \\
\hline \multirow[t]{3}{*}{ Guanfacine } & IR Guanfacine (Tenex) & $\begin{array}{c}\text { Initial } 1 \mathrm{mg} \text { daily; titrate as needed up to } 4 \text { mg MDD; } \\
\text { twice daily }\end{array}$ & $\begin{array}{l}12 \text { to } 24 \\
\text { hours }\end{array}$ & Same & Same \\
\hline & ER guanfacine (Intuniv) & Initial $1 \mathrm{mg}$; up to $4 \mathrm{mg}$; once daily & $\begin{array}{c}\sim 24 \\
\text { hours }\end{array}$ & Same & Same \\
\hline & & ANTIDEPRESSANTS & & & \\
\hline \multirow[t]{4}{*}{ NDRI } & Buproprion & $\begin{array}{l}\text { Initial: lesser of } 3 \mathrm{mg} / \mathrm{Kg} / \mathrm{d} \text { or } 150 \mathrm{mg} \text {; Maximum: Lesser } \\
\text { of } 6 \mathrm{mg} / \mathrm{Kg} / \mathrm{d} \text { or } 450 \mathrm{mg} \text {; No singled does greater than } \\
150 \mathrm{mg} ; 2 \text { to } 3 \text { times a day }\end{array}$ & $\begin{array}{l}8 \text { to } 12 \\
\text { hours }\end{array}$ & $\begin{array}{l}N \text { and } D \text { reuptake } \\
\text { inhibition }\end{array}$ & $\begin{array}{c}\text { Insomnia, decreased appetite, irritability, } \\
\text { anticholinergic (dry mouth, Gl etc.), decreased } \\
\text { seizure threshold }\end{array}$ \\
\hline & IR (Wellbutrin) & & & Same & Same \\
\hline & ER (Wellbutrin SR) & Twice daily & $\begin{array}{l}12 \text { to } 24 \\
\text { hours }\end{array}$ & Same & Same \\
\hline & (Wellbutrin XL) & Once daily & 24 hours & Same & Same \\
\hline SNRI's (Tricyclics) & Imipramine (Tofranil) & $\begin{array}{c}\text { Initial: } 1 \mathrm{mg} / \mathrm{Kg} / \mathrm{d} \text {; Maximum: Lesser of } 4 \mathrm{mg} / \mathrm{Kg} / \mathrm{d} \text { or } \\
200 \mathrm{mg} ; 1 \text { to } 2 \text { times per day; obtain baseline EKG; } \\
\text { Monitor serum levels }\end{array}$ & $\begin{array}{l}12 \text { to } 24 \\
\text { hours }\end{array}$ & $\begin{array}{l}N \text { and Serotonin } \\
\text { reuptake blockade }\end{array}$ & $\begin{array}{l}\text { Sedation, Cardiac increase heart rate, } \\
\text { arrhythmias, anticholinergic (dry mouth, Gl, } \\
\text { etc.), blurry vision }\end{array}$ \\
\hline
\end{tabular}

= Dopamine, $\mathrm{N}=$ Norepinephrine $\mathrm{S}=$ Serotonin, $\mathrm{IR}=\mathrm{Immediate}$ Release, $\mathrm{MPH}=$ Methylphenidate, $\mathrm{mg} / \mathrm{kg}=$ milligrams $/ \mathrm{kilogram}$, qhs $=$ before bed 
by the FDA for coadministration with stimulant medication.

Several reviews on the use of atomoxetine have been published recently $[76,77]$, and studies in populations around the world have continued to confirm its efficacy [78-81], including for children with oppositional defiant disorder [82] or those who have received previous stimulant therapy [83]. When atomoxetine is administered once daily, some evidence suggests that morning dosing may be more efficacious, but evening dosing may be more tolerable [84]. In adolescents, doses in the higher ranges have been associated with greater long-term efficacy [85]. Because atomoxetine has been rarely associated with acute suicidality [86], it has been given a 'black box' warning. As with stimulant treatment, atomoxetine rarely completely normalizes behavior [87], but symptom improvement is often reflected in gains in social and behavioral function [88].

The $\alpha$-2-adrenergic agonists clonidine and guanfacine have long been known to be of some assistance in treating ADHD [89]. Recently, once-daily extended-release guanfacine has proven effective in both short-term $[90,91]$ and long-term studies [92,93]. Sedation is a common side-effect, which diminishes over time [94].

Response to single-agent treatment for ADHD often falls short of full remission. Recent studies have shown that adding clonidine to methylphenidate [95], extended-release guanfacine to stimulants [96], or OROS methylphenidate to atomoxetine [97] improved residual ADHD symptoms and was well tolerated. The FDA recently approved a long-acting form of clonidine to be used in monotherapy or as an adjunctive therapy to stimulant medications.

Treatment of ADHD can result in alleviation of comorbid depression, anxiety, oppositional defiant disorder and/or aggression [98]. However, when this is not the case, polypharmacy targeting each condition may have added benefit without unacceptable side-effects. Examples include use of atomoxetine or methylphenidate in children being treated for bipolar spectrum disorders $[99,100]$ or borderline personality disorder [101], and atypical antipsychotics [102] or valproic acid preparations [103] for children with ADHD and aggression or bipolar disorder. For patients with autistic spectrum disorder, optimal results may require stimulants, SNRIs, antipsychotics and $\alpha$-2-agonists [104].

A number of reports have been published about the use of alternative and complementary medicines in the treatment of ADHD. In a small study, traditional Chinese medicines were found to compare favorably with methylphenidate [105]. Positive results were claimed for gingko biloba [106], but this failed in head-to-head comparison with methylphenidate [107]. Short-chain fatty acids [108] and omega-3/omega-6 fatty acids [109] have not been found to be efficacious. A meta-analysis of neurofeedback treatment studies reported encouraging results that suggested the approach would be more effective for inattention and impulsivity than for hyperactivity [110]. Cognitive training paradigms [111] have also been forwarded as a potential treatment stratagem, although these data require further research before any meaningful conclusions can be reached. At this point, the consensus for most alternative and complementary therapies is that these therapies are best used as a complement to ongoing pharmacotherapy rather than as an alternative.

\section{Adult ADHD treatment}

The need for treatment in adults with ADHD has been debated in the past, with reports of suboptimal response, diversion and abuse. There is a growing body of research on the treatment, and recent years have seen the creation of evidence-based guidelines [112]. Metaanalysis of pharmacological agents for managing adult ADHD have shown that stimulant medications are more effective than non-stimulant medications. This is in line with pediatric ADHD, for which stimulants are also generally considered the front-line approach [113]. Also similar to pediatric ADHD, stimulants are generally considered the front-line approach for managing adult ADHD. Unlike pediatric ADHD, all the agents approved by the FDA for treating adult ADHD are long-acting. Interestingly, some research suggests that only $49 \%$ of adults are prescribed long-acting agents [114]. The proportion of adults on long-acting agents is considerably lower than that for children.

Non-stimulant options are also similar to pediatric ADHD options, although bupropion and modafinil are used more often in adults than in children with ADHD. However, the only non-stimulant with FDA approval for adults with ADHD is atomoxetine.

The potential for diversion and misuse may be greater in adults than in children, as parents might control the medications for the latter. Stimulant misuse seems to be more common in those with comorbid alcohol-, drugand cigarette-related problems, and those with higher levels of ADHD symptoms [115]. In addition, long-acting stimulants are less likely to be misused or diverted than short-acting stimulants.

In pediatric $\mathrm{ADHD}$, a combined treatment approach generally consists of pharmacotherapy and some form of psychosocial intervention, generally consisting of training parents in behavioral management, consultation with teachers/school personnel and individual work with the child [116]. For example, behavioral parent training (BPT) programs seem to be effective for children with disruptive behaviors, irrespective of co-occurring attentional/hyperactive difficulties. BPT techniques generally consist of training parents in general operant 
conditioning techniques such as contingent application of reinforcement or punishment in response to appropriate/inappropriate behaviors. Reinforcement procedures have typically relied on praise, privileges or tokens, whereas punishment methods have usually been loss of positive attention, privileges or tokens, or formal 'time out' from reinforcement.

In adults, a combined treatment approach similarly typically consists of pharmacotherapy and psychosocial intervention. However, unlike pediatric ADHD, there is some evidence that CBT interventions are efficacious (please see Table 3 for list of common non-pharmacological interventions for managing ADHD).

CBT joins together cognitive and behavioral therapies, and gained popularity in the late 1960s as a treatment approach. Cognitive therapists believe that how a person interprets an event is more important than the actual event itself. Therefore, treatment focuses more on cognitions than on overt behaviors; reducing dysfunctional thoughts helps to improve adjustment [117]. Behavioral models emphasize the role of basic learning principles (operant conditioning, classic conditioning, observational learning) in developing and maintaining behavior, both adaptive and maladaptive. Rather than focusing on cognitions, behavioral therapy spotlights the stimuli and contingencies that maintain maladaptive behaviors. Treatments that are cognitive-behavioral in nature include both cognitive and behavioral procedures and have at their core three fundamental beliefs [118]: 1) cognitive activity affects behavior; 2) cognitive activity can be monitored and modified and 3) behavioral change can be produced by cognitive change.

Safren et al. developed a CBT program for adults with ADHD as a supplement to their medication treatment [119]. A recently published study suggests that, when compared with adults with ADHD who received relaxation training and educational support, adults with ADHD who received 12 sessions of CBT had lower selfreported ADHD symptoms and greater functional improvements as rated by a blinded assessor [119]. There were more treatment responders in the CBT group (53\%) relative to the relaxation training and educational support group (23\%), and gains were maintained over periods of 6 and 12 months [119].

Bramham et al. also developed a group CBT workshop program [120]. Using three 1-day workshops held monthly, six sessions were included in the program. The results suggested that, relative to the controls, adults with ADHD who participated in the workshop increased their knowledge of ADHD. However, less optimistically, one-third of participants dropped out during the course of the CBT workshop. Furthermore, both groups reported less depression and anxiety. Both groups also had improved self-esteem at the end of the study, but the intervention group reported a greater improvement in self-esteem [120]. Others have also recently developed group interventions relying on CBT strategies [121].

In sum, CBT seems to be a promising treatment approach to complement pharmacotherapy. At this point, there is limited evidence that CBT is efficacious on its own. However, when added to pharmacotherapy, emerging evidence suggests CBT improves treatment outcomes compared with medications alone.

\section{Challenges of treating ADHD}

There are several challenges associated with the treatment of people with ADHD. The first challenge is related to the clinical complexity of the cases themselves; the vast majority of people with ADHD, both child and adult, have a comorbid psychiatric disorder [122-125]. Thus, even relatively successful treatment of the ADHD symptoms may be associated with only modest functional improvements in the real world.

In the presence of significant comorbidity, complex combined treatments may be required, and the results may be frustrating. Diligent attempts to clarify the cooccurring conditions and related features (for example, poor social skills, low academic abilities become essential in cases resistant to treatment. Although most people with ADHD will respond favorably to pharmacological interventions [126], optimal functioning may not be attained. Even in non-comorbid ADHD cases, optimal functioning occurs in only roughly one in four children with ADHD [127,128]. Most patients show residual disabilities in several areas, including executive functioning, deficient emotional self-regulation, and 'real-world' functioning in school or employment, or in maintaining relationships. Some have suggested that ADHD is a disorder of performance, not knowledge [129]. Thus, despite reduced ADHD symptoms and knowing how best to manage their affairs, residual impulsivity often continues to negatively affect functioning. For this reason, establishing reasonable expectations with patients and parents may be crucial for the success and continuity of the treatment. Likewise, medications may improve some but not all aspects of cognitive functioning, and even when both symptoms and cognitive function are improved, the two are not necessarily correlated [130].

A second challenge in treating ADHD is related to the methods of treatment, and the optimization of the risk: benefit ratio. Optimization of the treatment response often requires careful adjustments in doses and particular distributions of the doses during the day to maximize the effect of medications at the point of performance. Combined pharmacotherapy (for example, antidepressant plus stimulant for ADHD and comorbid depression) is often needed for patients with comorbid disorders, and is sometimes indicated when ADHD is 


\begin{tabular}{|c|c|}
\hline Name & Description \\
\hline $\begin{array}{l}\text { Parent training in behavior } \\
\text { management }\end{array}$ & $\begin{array}{l}\text { A training intervention is to gather a detailed accounting of behavioral problems including when and in what } \\
\text { situations misbehaviors occur. It is also useful to record how parents and other adults react to the behaviors, and } \\
\text { what subsequent interactions take place as a result of those reactions. In sum, what are the social contingencies } \\
\text { that might be cueing, exacerbating or sustaining inappropriate behavior, if any? What disciplinary methods are } \\
\text { used in the home now and in the past, and what formalized help have parents sought and obtained for managing } \\
\text { the problems? Both parents need to be involved if both have contact with the child. At the very least, the non- } \\
\text { attending parent must be supportive of the one attending training if the transfer of skills from the group to the } \\
\text { home setting is to be enhanced. If others regularly care for the child, they may also be involved in the training, so } \\
\text { that the child experiences consistency across the routine caregivers in his life. }\end{array}$ \\
\hline School interventions & $\begin{array}{l}\text { Often include alterations to the curriculum and workload to better mesh with the limited attention, persistence } \\
\text { and disorganization of the child with ADHD; special educational services ('push-in' or mainstreaming assistance to } \\
\text { regular teachers; 'pull-out' services to focus on more individualized child training, self-contained classes); increases } \\
\text { in sources of positive reinforcement for work productivity; occasional use of immediate and systematic negative } \\
\text { consequences for disruptive or inappropriate behavior; implementation of a daily school behavior report card (the } \\
\text { ratings on which are linked to a home token economy), peer-tutoring or other innovative approaches to using } \\
\text { peer influence to achieve classroom goals; and more communication with parents. In short, greater accountability } \\
\text { of the child to teachers and others, including more immediate, frequent and salient feedback for performance, and } \\
\text { increased structuring of the classroom environment and teaching materials have all been shown to benefit the } \\
\text { child with ADHD in school. }\end{array}$ \\
\hline Cognitive behavioral therapy & $\begin{array}{l}\text { The emphasis on the process of restructuring or modifying an individual's thoughts to create behavioral effects is } \\
\text { what differentiates CBT therapists from behavioral therapists. Aspects of CBT that differentiate the treatment from } \\
\text { other therapeutic orientations such as psychodynamic therapy and interpersonal therapy include the following. } \\
\text { - Use of homework and outside-of-session activities. } \\
\text { - The CBT therapist is more active and directs session activity. } \\
\text { - CBT focus is clearly on the future. } \\
\text { - The CBT therapist explicitly teaches skills for coping with symptoms. } \\
\text { - The CBT therapist focuses on cognitive experiences (especially dysfunctional thoughts and beliefs). } \\
\text { - The therapist provides explicit information to the patient about the treatment, the disorder and its symptoms. }\end{array}$ \\
\hline
\end{tabular}

the only presenting problem. Adjunct psychosocial treatments are often useful, but these should be targeted to patients based on a needs assessment.

Possibly as a function of the disorder itself, non-adherence to treatment regimens is high in ADHD [131]. In addition to the disorganization inherent in the disorder, other contributors to poor treatment adherence may be denial, externalization of the problem and medication side-effects [131]. Little is known about predictors of long-term adherence, so more work is needed to improve this crucial component of treatment efficacy.

In sum, despite considerable advances in our understanding and treating ADHD, the disorder remains difficult to manage. Poor treatment adherence and psychiatric comorbidity clearly complicate treatment and negatively affect outcomes.

\section{Conclusions}

Cognitive neuroscience has permitted a greater understanding of ADHD. Recent research and novel drug developments have provided new treatment options for adolescents and adults with ADHD. New stimulant formulations have made it possible to tailor treatment to the duration of efficacy required by patients and to help mitigate the potential for abuse, misuse and diversion. Although they tend to be less efficacious than stimulants, new non-stimulant options also allow for extended duration of treatment without the adverse consequences associated with stimulant therapy. Progress in non-medical therapies now provides several options for patients who cannot or will not use medications, and for the many medication-treated patients who continue to show residual disability.

Looking toward the future, research will need to address several unmet needs. Many treated people with ADHD continue to have problems with executive functioning and deficient emotional self-regulation. These problems persist in many patients even when the core ADHD symptoms (as outlined in the Diagnostic and Statistical Manual of Mental Disorders, Fourth edition (DSM-IV)) are effectively treated. Future treatment development should aim at developing both psychosocial and medical treatments for these areas of difficulty. Future treatment research should also work to define and achieve optimal treatment outcomes for people with ADHD. Although current treatments are effective for achieving substantial symptom reduction in most patients, more work is needed to achieve full symptom reduction, and to reduce the burden of ADHD-associated disabilities.

There are also diagnostic challenges for clinicians that could be addressed by future research. ADHD symptoms, especially hyperactive-impulsive symptoms, tend to decline through adolescence into adulthood, so that 
the adult presentation of ADHD differs somewhat from the childhood presentation. Helping clinicians understand these differences, and how such differences should affect the application of diagnostic criteria requires more work.

Ideally, medical and psychological treatments should be tailored to the underlying pathophysiology of the patient. Theoretically, this should be possible by using the scientific literature on the neurobiology of ADHD with treatment outcome studies, as it is possible that patients with specific brain-imaging abnormalities or genetic variants would have different responses to treatments. To date, most of this work has been done in the area of pharmacogenetics which, although promising, cannot yet guide treatment choices [132-134]

In summary, although the science of ADHD and its application to diagnosis and treatment have made great strides, more work is needed to improve the lives of patients and families affected by the disorder.

\section{List of Abbreviation}

ADHD: attention deficit/hyperactivity disorder; CBT: cognitive behavioral therapy; LDX: lisdexamfetamine dimesylate; OROS: osmotic-release oral system; SNRI: Serotonin-norepinephrine reuptake inhibitor

\section{Acknowledgements and funding} None

\section{Authors' contributions}

All authors have been involved in drafting the manuscript or critically revising it or important intellectual content, and have given final approval of the version to be published.

\section{Competing interests}

Kevin M. Antshel*, Teresa M. Hargrave, Mihai Simonescu, Prashant Kaul, Kaitlin Hendricks and Stephen V. Faraone

$\mathrm{KMA}, \mathrm{TMH}, \mathrm{MH}, \mathrm{PK}$, and $\mathrm{KH}$ report no biomedical financial interests or potential conflicts of interest. SVF has in the past year received consulting fees and has been on Advisory Boards for Eli Lilly, Ortho-McNeil and Shire Development and has received research support from Shire and the National Institutes of Health; in previous years, has received consulting fees or has been on advisory boards or has been a speaker for Shire, McNeil, Janssen, Novartis, Pfizer, Ortho-McNeil and Eli Lilly; in previous years has received research support from Eli Lilly, Shire, Pfizer and the National Institutes of Health, and has a published book with Guilford Press: Straight Talk About Your Child's Mental Health.

Received: 28 October 2010 Accepted: 10 June 2011

Published: 10 June 2011

\section{References}

1. APA: DSM-IV-TR. Washington, DC: American Psychiatric Association; 2000.

2. Barbaresi WJ, Katusic SK, Colligan RC, Pankratz VS, Weaver AL, Weber KJ, Mrazek DA, Jacobsen SJ: How common is attention-deficit/hyperactivity disorder? Incidence in a population-based birth cohort in Rochester, Minn. Arch Pediatr Adolesc Med 2002, 156(3):217-224.

3. Kessler RC, Adler L, Barkley R, Biederman J, Conners CK, Demler O, Faraone SV, Greenhill LL, Howes MJ, Secnik K, et al: The prevalence and correlates of adult ADHD in the United States: results from the National Comorbidity Survey Replication. American Journal of Psychiatry 2006 163(4):716-723.

4. Lavigne JV, Gibbons RD, Christoffel KK, Arend R, Rosenbaum D, Binns H, Dawson N, Sobel H, Isaacs C: Prevalence rates and correlates of psychiatric disorders among preschool children. J Am Acad Child Adolesc Psychiatry 1996, 35(2):204-214.

5. Faraone SV, Sergeant J, Gillberg C, Biederman J: The worldwide prevalence of ADHD: is it an American condition? World Psychiatry 2003, 2(2):104-113.

6. Polanczyk G, de Lima MS, Horta BL, Biederman J, Rohde LA: The worldwide prevalence of ADHD: a systematic review and metaregression analysis. Am J Psychiatry 2007, 164(6):942-948.

7. Bloom B, Cohen RA: Summary health statistics for U.S. children: National Health Interview Survey, 2006.Edited by: Statistics VH 2007, 234:1-79.

8. Levy F, Hay DA, McStephen M, Wood C, Waldman I: Attention-deficit hyperactivity disorder: a category or a continuum? Genetic analysis of a large-scale twin study. J Am Acad Child Adolesc Psychiatry 1997, 36(6):737-744.

9. Angold A, Costello EJ, Erkanli A: Comorbidity. J Child Psychol Psychiatry 1999, 40(1):57-87.

10. Biederman J, Newcorn J, Sprich S: Comorbidity of attention deficit hyperactivity disorder with conduct, depressive, anxiety, and other disorders. American Journal of Psychiatry 1991, 148(5):564-577.

11. Borland BL, Heckman HK: Hyperactive boys and their brothers: A 25-year follow-up study. Archives of General Psychiatry 1976, 33:669-675.

12. Morrison JR: Adult psychiatric disorders in parents of hyperactive children. American Journal of Psychiatry 1980, 137:825-827.

13. Biederman J, Faraone SV, Spencer T, Wilens T, Norman D, Lapey KA, Mick E, Lehman BK, Doyle A: Patterns of psychiatric comorbidity, cognition, and psychosocial functioning in adults with attention deficit hyperactivity disorder. Am J Psychiatry 1993, 150(12):1792-1798.

14. Heiligenstein E, Conyers LM, Berns AR, Miller MA: Preliminary normative data on DSM-IV attention deficit hyperactivity disorder in college students. J Am Coll Health 1998, 46(4):185-188

15. Murphy K, Barkley RA: Attention deficit hyperactivity disorder adults: comorbidities and adaptive impairments. Compr Psychiatry 1996 37(6):393-401.

16. Shekim WO, Asarnow RF, Hess E, Zaucha K, Wheeler N: A clinical and demographic profile of a sample of adults with attention deficit hyperactivity disorder, residual state. Compr Psychiatry 1990, 31(5):416-425.

17. Barkley R, Murphy K, Fischer M: ADHD in adults: what the science says. New York: Guilford Press; 2007.

18. Lahey BB, Applegate B, McBurnett K, Biederman J, Greenhill L, Hynd GW, Barkley RA, Newcorn J, Jensen P, Richters J, et al: DSM-IV field trials for attention deficit hyperactivity disorder in children and adolescents. Am J Psychiatry 1994, 151(11):1673-1685.

19. Lopez-Munoz F, Alamo C, Quintero-Gutierrez FJ, Garcia-Garcia P: A bibliometric study of international scientific productivity in attentiondeficit hyperactivity disorder covering the period 1980-2005. Eur Child Adolesc Psychiatry 2008, 17(6):381-391.

20. Levy F: Dopamine vs noradrenaline: inverted-U effects and ADHD theories. Aust N Z J Psychiatry 2009, 43(2):101-108.

21. Stahl SM: Mechanism of action of stimulants in attention-deficit/ hyperactivity disorder. J Clin Psychiatry 2010, 71(1):12-13.

22. Swanson JM, Volkow ND: Psychopharmacology: concepts and opinions about the use of stimulant medications. J Child Psychol Psychiatry 2009, 50(1-2):180-193.

23. Stahl SM: Mechanism of action of alpha 2A-adrenergic agonists in attention-deficit/hyperactivity disorder with or without oppositional symptoms. J Clin Psychiatry 2010, 71(3):223-224.

24. Daughton JM, Kratochvil CJ: Review of ADHD pharmacotherapies: advantages, disadvantages, and clinical pearls. J Am Acad Child Adolesc Psychiatry 2009, 48(3):240-248.

25. May DE, Kratochvil CJ: Attention-deficit hyperactivity disorder: recent advances in paediatric pharmacotherapy. Drugs 2010, 70(1):15-40.

26. Chen CY, Gerhard T, Winterstein AG: Determinants of initial pharmacological treatment for youths with attention-deficit/ hyperactivity disorder. J Child Adolesc Psychopharmacol 2009, 19(2):187-195

27. Olfson M, Marcus S, Wan G: Stimulant dosing for children with ADHD: a medical claims analysis. J Am Acad Child Adolesc Psychiatry 2009, 48(1):51-59.

28. Fulton BD, Scheffler RM, Hinshaw SP, Levine $P$, Stone $S$, Brown $\pi$, Modrek S: National variation of ADHD diagnostic prevalence and medication use: health care providers and education policies. Psychiatr Serv 2009, 60(8):1075-1083. 
29. Janknegt R, Faber A, Rodrigues Pereira R, Kalverdijk LJ: InforMatrix for attention deficit hyperactivity disorder. Expert Opin Pharmacother 2009, 10(5):755-772.

30. Harpur RA, Thompson M, Daley D, Abikoff H, Sonuga-Barke EJ: The attention-deficit/hyperactivity disorder medication-related attitudes of patients and their parents. J Child Adolesc Psychopharmacol 2008, 18(5):461-473.

31. Berger I, Dor T, Nevo Y, Goldzweig G: Attitudes toward attention-deficit hyperactivity disorder (ADHD) treatment: parents' and children's perspectives. J Child Neurol 2008, 23(9):1036-1042.

32. Pappadopulos E, Jensen PS, Chait AR, Arnold LE, Swanson JM, Greenhill LL, Hechtman L, Chuang S, Wells KC, Pelham W, et al: Medication adherence in the MTA: saliva methylphenidate samples versus parent report and mediating effect of concomitant behavioral treatment. J Am Acad Child Adolesc Psychiatry 2009, 48(5):501-510.

33. Rabbani A, Alexander GC: Impact of family structure on stimulant use among children with attention-deficit/hyperactivity disorder. Health Ser Res 2009, 44(6):2060-2078.

34. Brinkman WB, Sherman SN, Zmitrovich AR, Visscher MO, Crosby LE, Phelan KJ, Donovan EF: Parental angst making and revisiting decisions about treatment of attention-deficit/hyperactivity disorder. Pediatrics 2009, 124(2):580-589

35. Thorell LB, Dahlstrom K: Children's self-reports on perceived effects on taking stimulant medication for ADHD. J Atten Disord 2009, 12(5):460-468.

36. McCarthy S, Asherson P, Coghill D, Hollis C, Murray M, Potts L, Sayal K, de Soysa R, Taylor E, Williams T, et al: Attention-deficit hyperactivity disorder: treatment discontinuation in adolescents and young adults. $\mathrm{Br} J$ Psychiatry 2009, 194(3):273-277.

37. Faraone SV, Biederman J, Spencer TJ, Aleardi M: Comparing the efficacy of medications for ADHD using meta-analysis. MedGenMed 2006, 8(4):4

38. Chavez B, Sopko MA, Ehret MJ, Paulino RE, Goldberg KR, Angstadt K, Bogart GT: An update on central nervous system stimulant formulations in children and adolescents with attention-deficit/hyperactivity disorder. Ann Pharmacother 2009, 43(6):1084-1095.

39. Kim Y, Shin MS, Kim JW, Yoo HJ, Cho SC, Kim BN: Neurocognitive effects of switching from methylphenidate-IR to OROS-methylphenidate in children with ADHD. Hum Psychopharmacol 2009, 24(2):95-102.

40. Chou WJ, Chou MC, Tzang RF, Hsu YC, Gau SS, Chen SJ, Wu YY, Huang YF, Liang HY, Cheng H: Better efficacy for the osmotic release oral system methylphenidate among poor adherents to immediate-release methylphenidate in the three ADHD subtypes. Psychiatry Clin Neurosci 2009, 63(2):167-175.

41. Abikoff H, Nissley-Tsiopinis J, Gallagher R, Zambenedetti M, Seyffert M, Boorady R, McCarthy J: Effects of MPH-OROS on the organizational, time management, and planning behaviors of children with ADHD. J Am Acad Child Adolesc Psychiatry 2009, 48(2):166-175.

42. Childress AC, Spencer T, Lopez F, Gerstner O, Thulasiraman A, Muniz R, Post A: Efficacy and safety of dexmethylphenidate extended-release capsules administered once daily to children with attention-deficit/ hyperactivity disorder. J Child Adolesc Psychopharmacol 2009, 19(4):351-361.

43. Moen MD, Keam SJ: Dexmethylphenidate extended release: a review of its use in the treatment of attention-deficit hyperactivity disorder. CNS Drugs 2009, 23(12):1057-1083.

44. Faraone SV, Glatt SJ, Bukstein OG, Lopez FA, Arnold LE, Findling RL: Effects of once-daily oral and transdermal methylphenidate on sleep behavior of children with ADHD. J Atten Disord 2009, 12(4):308-315.

45. Wilens TE, Hammerness $P$, Martelon M, Brodziak K, Utzinger L, Wong P: A controlled trial of the methylphenidate transdermal system on beforeschool functioning in children with attention-deficit/hyperactivity disorder. J Clin Psychiatry 71(5):548-556.

46. Manos M, Frazier TW, Landgraf JM, Weiss M, Hodgkins P: HRQL and medication satisfaction in children with ADHD treated with the methylphenidate transdermal system. Curr Med Res Opin 2009, 25(12):3001-3010.

47. Gonzalez MA, Campbell D, Rubin J: Effects of application to two different skin sites on the pharmacokinetics of transdermal methylphenidate in pediatric patients with attention-deficit/hyperactivity disorder. J Child Adolesc Psychopharmacol 2009, 19(3):227-232.

48. Garcia SP, Guimaraes J, Zampieri JF, Martinez AL, Polanczyk G, Rohde LA Response to methylphenidate in children and adolescents with ADHD: does comorbid anxiety disorders matters? J Neural Transm 2009, 116(5):631-636.

49. Biederman J, Monuteaux MC, Spencer T, Wilens TE, Faraone SV: Do stimulants protect against psychiatric disorders in youth with ADHD? A 10-year follow-up study. Pediatrics 2009, 124(1):71-78.

50. Wilens TE, Adamson J, Monuteaux MC, Faraone SV, Schillinger M, Westerberg D, Biederman J: Effect of prior stimulant treatment for attention-deficit/hyperactivity disorder on subsequent risk for cigarette smoking and alcohol and drug use disorders in adolescents. Arch Pediatr Adolesc Med 2008, 162(10):916-921.

51. Bloch MH, Panza KE, Landeros-Weisenberger A, Leckman JF: Meta-analysis: treatment of attention-deficit/hyperactivity disorder in children with comorbid tic disorders. J Am Acad Child Adolesc Psychiatry 2009, 48(9):884-893.

52. Gadow KD, Nolan EE, Sverd J, Sprafkin J, Schneider J: Methylphenidate in children with oppositional defiant disorder and both comorbid chronic multiple tic disorder and ADHD. J Child Neurol 2008, 23(9):981-990.

53. Sonuga-Barke EJ, Coghill D, Wigal T, DeBacker M, Swanson J: Adverse reactions to methylphenidate treatment for attention-deficit/ hyperactivity disorder: structure and associations with clinical characteristics and symptom control. J Child Adolesc Psychopharmacol 2009, 19(6):683-690.

54. Yu ZJ, Parker-Kotler C, Tran K, Weller RA, Weller EB: Peripheral vasculopathy associated with psychostimulant treatment in children with attentiondeficit/hyperactivity disorder. Curr Psychiatry Rep 2010, 12(2):111-115.

55. Hammerness P, Wilens T, Mick E, Spencer T, Doyle R, McCreary M, Becker J, Biederman J: Cardiovascular effects of longer-term, high-dose OROS methylphenidate in adolescents with attention deficit hyperactivity disorder. J Pediatr 2009, 155(1):84-89, 89 e81.

56. Mahon AD, Stephens BR, Cole AS: Exercise responses in boys with attention deficit/hyperactivity disorder: effects of stimulant medication. $J$ Atten Disord 2008, 12(2):170-176.

57. Winterstein AG, Gerhard T, Shuster J, Saidi A: Cardiac safety of methylphenidate versus amphetamine salts in the treatment of ADHD. Pediatrics 2009, 124(1):e75-80.

58. Warren AE, Hamilton RM, Belanger SA, Gray C, Gow RM, Sanatani S, Cote JM, Lougheed J, LeBlanc J, Martin S, et al: Cardiac risk assessment before the use of stimulant medications in children and youth: A joint position statement by the Canadian Paediatric Society, the Canadian Cardiovascular Society, and the Canadian Academy of Child and Adolescent Psychiatry. Can J Cardiol 2009, 25(11):625-630.

59. Banaschewski T: Joint position of the Guideline Group of the European Network for Hyperkintetic Disorders (EUNETHYDIS) and the German Central ADHD Network for ECG Recording on methylphenidate prescriptions. Z Kinder Jugendpsychiatr Psychother 2008, 36(6):437-439.

60. Ponsa I, Ramos-Quiroga JA, Ribases M, Bosch R, Bielsa A, Ordeig MT, Morell M, Miro R, de Cid R, Estivill X, et al: Absence of cytogenetic effects in children and adults with attention-deficit/hyperactivity disorder treated with methylphenidate. Mutat Res 2009, 666(1-2):44-49.

61. Walitza S, Kampf K, Artamonov N, Romanos M, Gnana Oli R, Wirth S, Warnke A, Gerlach M, Stopper H: No elevated genomic damage in children and adolescents with attention deficit/hyperactivity disorder after methylphenidate therapy. Toxicol Lett 2009, 184(1):38-43.

62. Faraone SV, Biederman J, Morley CP, Spencer TJ: Effect of stimulants on height and weight: a review of the literature. J Am Acad Child Adolesc Psychiatry 2008, 47(9):994-1009.

63. Graham J, Banaschewski T, Buitelaar J, Coghill D, Danckaerts M, Dittmann RW, Dopfner M, Hamilton R, Hollis C, Holtmann M, et al: European guidelines on managing adverse effects of medication for ADHD. Eur Child Adolesc Psychiatry 2011, 20(1):17-37.

64. Setlik J, Bond GR, Ho M: Adolescent prescription ADHD medication abuse is rising along with prescriptions for these medications. Pediatrics 2009, 124(3):875-880.

65. Rabiner DL, Anastopoulos AD, Costello EJ, Hoyle RH, McCabe SE, Swartzwelder HS: The misuse and diversion of prescribed ADHD medications by college students. J Atten Disord 2009, 13(2):144-153.

66. Faraone SV, Wilens TE: Effect of stimulant medications for attentiondeficit/hyperactivity disorder on later substance use and the potential for stimulant misuse, abuse, and diversion. J Clin Psychiatry 2007, 68(Suppl 11):15-22. 
67. Kollins SH: ADHD, substance use disorders, and psychostimulant treatment: current literature and treatment guidelines. J Atten Disord 2008, 12(2):115-125.

68. Najib J: The efficacy and safety profile of lisdexamfetamine dimesylate, a prodrug of d-amphetamine, for the treatment of attention-deficit/ hyperactivity disorder in children and adults. Clin Ther 2009, 31(1):142-176.

69. Antonucci D, Kunins C, Manos M, Lopez FA, Kerney DL: Assessing effects of treatment with lisdexamfetamine dimesylate for pediatric ADHD using a parental survey. CNS Spectr 2010, 15(4):248-256.

70. Findling RL, Ginsberg LD, Jain R, Gao J: Effectiveness, safety, and tolerability of lisdexamfetamine dimesylate in children with attentiondeficit/hyperactivity disorder: an open-label, dose-optimization study. $J$ Child Adolesc Psychopharmacol 2009, 19(6):649-662

71. Faraone SV, Spencer TJ, Kollins SH, Glatt SJ: Effects of lisdexamfetamine dimesylate treatment for ADHD on growth. J Am Acad Child Adolesc Psychiatry 49(1):24-32.

72. Boellner SW, Stark JG, Krishnan S, Zhang Y: Pharmacokinetics of lisdexamfetamine dimesylate and its active metabolite, d-amphetamine, with increasing oral doses of lisdexamfetamine dimesylate in children with attention-deficit/hyperactivity disorder: a single-dose, randomized, open-label, crossover study. Clin Ther 32(2):252-264.

73. Kahbazi M, Ghoreishi A, Rahiminejad F, Mohammadi MR, Kamalipour A Akhondzadeh S: A randomized, double-blind and placebo-controlled trial of modafinil in children and adolescents with attention deficit and hyperactivity disorder. Psychiatry Res 2009, 168(3):234-237.

74. Arabgol F, Panaghi L, Hebrani P: Reboxetine versus methylphenidate in treatment of children and adolescents with attention deficithyperactivity disorder. Eur Child Adolesc Psychiatry 2009, 18(1):53-59.

75. Cohen-Yavin I, Yoran-Hegesh R, Strous RD, Kotler M, Weizman A, Spivak B: Efficacy of reboxetine in the treatment of attention-deficit/hyperactivity disorder in boys with intolerance to methylphenidate: an open-label, 8 week, methylphenidate-controlled trial. Clin Neuropharmacol 2009 32(4):179-182.

76. Newcorn JH, Sutton VK, Weiss MD, Sumner CR: Clinical responses to atomoxetine in attention-deficit/hyperactivity disorder: the Integrated Data Exploratory Analysis (IDEA) study. J Am Acad Child Adolesc Psychiatry 2009, 48(5):511-518.

77. Garnock-Jones KP, Keating GM: Atomoxetine: a review of its use in attention-deficit hyperactivity disorder in children and adolescents. Paediatr Drugs 2009, 11(3):203-226.

78. Svanborg P, Thernlund G, Gustafsson PA, Hagglof B, Poole L, Kadesjo B: Efficacy and safety of atomoxetine as add-on to psychoeducation in the treatment of attention deficit/hyperactivity disorder: a randomized, double-blind, placebo-controlled study in stimulant-naive Swedish children and adolescents. Eur Child Adolesc Psychiatry 2009, 18(4):240-249.

79. Martenyi F, Zavadenko NN, Jarkova NB, Yarosh AA, Soldatenkova VO, Bardenstein LM, Kozlova IA, Neznanov NG, Maslova OI, Petrukhin AS, et al: Atomoxetine in children and adolescents with attention-deficit/ hyperactivity disorder: a 6-week, randomized, placebo-controlled double-blind trial in Russia. Eur Child Adolesc Psychiatry 2010, 19(1):57-66.

80. Takahashi M, Takita Y, Yamazaki K, Hayashi T, Ichikawa H, Kambayashi Y, Koeda T, Oki J, Saito K, Takeshita K, et al: A randomized, double-blind, placebo-controlled study of atomoxetine in Japanese children and adolescents with attention-deficit/hyperactivity disorder. J Child Adolesc Psychopharmacol 2009, 19(4):341-350.

81. Durell TM, Pumariega AJ, Rothe EM, Tamayo JM, Baron D, Williams D: Effects of open-label atomoxetine on African-American and Caucasian pediatric outpatients with attention-deficit/hyperactivity disorder. Ann Clin Psychiatry 2009, 21(1):26-37.

82. Dell'Agnello G, Maschietto D, Bravaccio C, Calamoneri F, Masi G, Curatolo P, Besana D, Mancini F, Rossi A, Poole L, et al: Atomoxetine hydrochloride in the treatment of children and adolescents with attention-deficit/ hyperactivity disorder and comorbid oppositional defiant disorder: A placebo-controlled Italian study. Eur Neuropsychopharmacol 2009, 19(11):822-834.

83. Hammerness P, Doyle R, Kotarski M, Georgiopoulos A, Joshi G, Zeitlin S, Biederman J: Atomoxetine in children with attention-deficit hyperactivity disorder with prior stimulant therapy: a prospective open-label study. Eur Child Adolesc Psychiatry 2009, 18(8):493-498.
84. Block SL, Kelsey D, Coury D, Lewis D, Quintana H, Sutton V, Schuh K, Allen AJ, Sumner C: Once-daily atomoxetine for treating pediatric attention-deficit/hyperactivity disorder: comparison of morning and evening dosing. Clin Pediatr (Phila) 2009, 48(7):723-733.

85. Wietecha LA, Williams DW, Herbert M, Melmed RD, Greenbaum M, Schuh K Atomoxetine treatment in adolescents with attention-deficit/ hyperactivity disorder. J Child Adolesc Psychopharmacol 2009, 19(6):719-730

86. Paxton GA, Cranswick NE: Acute suicidality after commencing atomoxetine. J Paediatr Child Health 2008, 44(10):596-598.

87. Whalen CK, Henker B, Ishikawa SS, Emmerson NA, Swindle R, Johnston JA: Atomoxetine versus stimulants in the community treatment of children with ADHD: an electronic diary study. J Atten Disord 2010, 13(4):391-400.

88. Buitelaar JK, Wilens TE, Zhang S, Ning Y, Feldman PD: Comparison of symptomatic versus functional changes in children and adolescents with ADHD during randomized, double-blind treatment with psychostimulants, atomoxetine, or placebo. J Child Psychol Psychiatry 2009, 50(3):335-342

89. Scahill L: Alpha-2 adrenergic agonists in children with inattention, hyperactivity and impulsiveness. CNS Drugs 2009, 23(Suppl 1):43-49.

90. Sallee FR, McGough J, Wigal T, Donahue J, Lyne A, Biederman J: Guanfacine extended release in children and adolescents with attentiondeficit/hyperactivity disorder: a placebo-controlled trial. J Am Acad Child Adolesc Psychiatry 2009, 48(2):155-165

91. Biederman J, Melmed RD, Patel A, McBurnett K, Konow J, Lyne A, Scherer N A randomized, double-blind, placebo-controlled study of guanfacine extended release in children and adolescents with attention-deficit/ hyperactivity disorder. Pediatrics 2008, 121(1):e73-84

92. Sallee FR, Lyne A, Wigal T, McGough JJ: Long-term safety and efficacy of guanfacine extended release in children and adolescents with attentiondeficit/hyperactivity disorder. J Child Adolesc Psychopharmacol 2009, 19(3):215-226.

93. Biederman J, Melmed RD, Patel A, McBurnett K, Donahue J, Lyne A: Longterm, open-label extension study of guanfacine extended release in children and adolescents with ADHD. CNS Spectr 2008, 13(12):1047-1055.

94. Faraone SV, Glatt SJ: Effects of extended-release guanfacine on ADHD symptoms and sedation-related adverse events in children with ADHD. $J$ Atten Disord 2010, 13(5):532-538.

95. Cannon M, Pelham WH, Sallee FR, Palumbo DR, Bukstein O, Daviss WB: Effects of clonidine and methylphenidate on family quality of life in attention-deficit/hyperactivity disorder. J Child Adolesc Psychopharmacol 2009, 19(5):511-517.

96. Spencer TJ, Greenbaum M, Ginsberg LD, Murphy WR: Safety and effectiveness of coadministration of guanfacine extended release and psychostimulants in children and adolescents with attention-deficit/ hyperactivity disorder. J Child Adolesc Psychopharmacol 2009, 19(5):501-510.

97. Wilens TE, Hammerness P, Utzinger L, Schillinger M, Georgiopoulous A, Doyle RL, Martelon M, Brodziak K: An open study of adjunct OROS methylphenidate in children and adolescents who are atomoxetine partial responders: I. Effectiveness. J Child Adolesc Psychopharmacol 2009, 19(5):485-492.

98. Frolich J, Lehmkuhl G, Dopfner M: Algorithms for the medical treatment of Attention-Deficit/Hyperactivity Disorder with specific co-morbidities. Z Kinder Jugendpsychiatr Psychother 2010, 38(1):7-20.

99. Chang K, Nayar D, Howe M, Rana M: Atomoxetine as an adjunct therapy in the treatment of co-morbid attention-deficit/hyperactivity disorder in children and adolescents with bipolar I or II disorder. J Child Adolesc Psychopharmacol 2009, 19(5):547-551.

100. Zeni CP, Tramontina S, Ketzer CR, Pheula GF, Rohde LA: Methylphenidate combined with aripiprazole in children and adolescents with bipolar disorder and attention-deficit/hyperactivity disorder: a randomized crossover trial. J Child Adolesc Psychopharmacol 2009, 19(5):553-561.

101. Golubchik P, Sever J, Weizman A: Influence of methylphenidate treatment on smoking behavior in adolescent girls with attention-deficit/ hyperactivity and borderline personality disorders. Clin Neuropharmacol 2009, 32(5):239-242.

102. Weiss M, Panagiotopoulos C, Giles L, Gibbins C, Kuzeljevic B, Davidson J, Harrison R: A naturalistic study of predictors and risks of atypical antipsychotic use in an attention-deficit/hyperactivity disorder clinic. J Child Adolesc Psychopharmacol 2009, 19(5):575-582 
103. Blader JC, Schooler NR, Jensen PS, Pliszka SR, Kafantaris V: Adjunctive divalproex versus placebo for children with $A D H D$ and aggression refractory to stimulant monotherapy. Am J Psychiatry 2009, 166(12):1392-1401.

104. Aman MG, Farmer CA, Hollway J, Arnold LE: Treatment of inattention, overactivity, and impulsiveness in autism spectrum disorders. Child Adolesc Psychiatr Clin N Am 2008, 17(4):713-738, vii.

105. Lan Y, Zhang LL, Luo R: Attention deficit hyperactivity disorder in children: comparative efficacy of traditional Chinese medicine and methylphenidate. J Int Med Res 2009, 37(3):939-948.

106. Niederhofer $\mathrm{H}$ : Ginkgo biloba treating patients with attention-deficit disorder. Phytother Res 2010, 24(1):26-27.

107. Salehi B, Imani R, Mohammadi MR, Fallah J, Mohammadi M, Ghanizadeh A Tasviechi AA, Vossoughi A, Rezazadeh SA, Akhondzadeh S: Ginkgo biloba for attention-deficit/hyperactivity disorder in children and adolescents: a double blind, randomized controlled trial. Prog Neuropsychopharmacol Biol Psychiatry 2010, 34(1):76-80.

108. Raz R, Carasso RL, Yehuda S: The influence of short-chain essential fatty acids on children with attention-deficit/hyperactivity disorder: a doubleblind placebo-controlled study. J Child Adolesc Psychopharmacol 2009, 19(2):167-177.

109. Johnson M, Ostlund S, Fransson G, Kadesjo B, Gillberg C: Omega-3/omega6 fatty acids for attention deficit hyperactivity disorder: a randomized placebo-controlled trial in children and adolescents. J Atten Disord 2009, 12(5):394-401.

110. Arns M, de Ridder S, Strehl U, Breteler M, Coenen A: Efficacy of neurofeedback treatment in ADHD: the effects on inattention, impulsivity and hyperactivity: a meta-analysis. Clin EEG Neurosci 2009, 40(3):180-189.

111. Klingberg T, Fernell E, Olesen PJ, Johnson M, Gustafsson P, Dahlstrom K, Gillberg CG, Forssberg $H$, Westerberg $H$ : Computerized training of working memory in children with ADHD-a randomized, controlled trial. J Am Acad Child Adolesc Psychiatry 2005, 44(2):177-186.

112. Kooij SJ, Bejerot S, Blackwell A, Caci H, Casas-Brugue M, Carpentier PJ, Edvinsson D, Fayyad J, Foeken K, Fitzgerald M, et al: European consensus statement on diagnosis and treatment of adult ADHD: The European Network Adult ADHD. BMC Psychiatry 2010, 10:67.

113. Faraone SV, Glatt SJ: A comparison of the efficacy of medications for adult attention-deficit/hyperactivity disorder using meta-analysis of effect sizes. J Clin Psychiatry 2009, 71(6):754-763.

114. Cascade $\mathrm{E}$, Kalali AH, Weisler RH: Short-acting versus long-acting medications for the treatment of ADHD. Psychiatry (Edgmont) 2008, 5(8):24-27.

115. Wilens TE, Adler LA, Adams J, Sgambati S, Rotrosen J, Sawtelle R, Utzinger L, Fusillo S: Misuse and diversion of stimulants prescribed for ADHD: a systematic review of the literature. J Am Acad Child Adolesc Psychiatry 2008, 47(1):21-31.

116. Antshel KM, Barkley R: Psychosocial interventions in attention deficit hyperactivity disorder. Child Adolesc Psychiatr Clin N Am 2008, 17(2):421-437, $x$

117. Ilardi SS, Craighead WE: The role of nonspecific factors in cognitivebehavior therapy for depression. Clinical Psychology: Science and Practice 1994, 1:138-156.

118. Blagys MD, Hilsenroth MJ: Distinctive activities of cognitive-behavioral therapy. A review of the comparative psychotherapy process literature. Clin Psychol Rev 2002, 22(5):671-706.

119. Safren SA, Sprich S, Mimiaga MJ, Surman C, Knouse L, Groves M, Otto MW: Cognitive behavioral therapy vs relaxation with educational support for medication-treated adults with ADHD and persistent symptoms: a randomized controlled trial. Jama 2010, 304(8):875-880.

120. Bramham J, Young S, Bickerdike A, Spain D, McCartan D, Xenitidis K: Evaluation of group cognitive behavioral therapy for adults with ADHD. J Atten Disord 2009, 12(5):434-441.

121. Solanto MV, Marks DJ, Mitchell KJ, Wasserstein J, Kofman MD: Development of a new psychosocial treatment for adult ADHD. J Atten Disord 2008, 11(6):728-736.

122. Wilens TE, Biederman J, Faraone SV, Martelon M, Westerberg D, Spencer TJ: Presenting ADHD symptoms, subtypes, and comorbid disorders in clinically referred adults with ADHD. J Clin Psychiatry 2009, 70(11):1557-1562.
123. Kadesjo B, Gillberg C: The comorbidity of ADHD in the general population of Swedish school-age children. J Child Psychol Psychiatry 2001, 42(4):487-492.

124. Rommelse NN, Altink ME, Fliers EA, Martin NC, Buschgens CJ, Hartman CA, Buitelaar JK, Faraone SV, Sergeant JA, Oosterlaan J: Comorbid problems in ADHD: degree of association, shared endophenotypes, and formation of distinct subtypes. Implications for a future DSM. J Abnorm Child Psychol 2009, 37(6):793-804.

125. Lavigne JV, Lebailly SA, Hopkins J, Gouze KR, Binns HJ: The prevalence of ADHD, ODD, depression, and anxiety in a community sample of 4-yearolds. J Clin Child Adolesc Psychol 2009, 38(3):315-328.

126. Elia J, Borcherding BG, Rapoport JL, Keysor CS: Methylphenidate and dextroamphetamine treatments of hyperactivity: are there true nonresponders? Psychiatry Res 1991, 36(2):141-155.

127. DuPaul GJ, Rapport MD: Does methylphenidate normalize the classroom performance of children with attention deficit disorder? J Am Acad Child Adolesc Psychiatry 1993, 32(1):190-198.

128. Greenhill LL, Abikoff HB, Arnold LE, Cantwell DP, Conners CK, Elliott G, Hechtman L, Hinshaw SP, Hoza B, Jensen PS, et al: Medication treatment strategies in the MTA Study: relevance to clinicians and researchers. Am Acad Child Adolesc Psychiatry 1996, 35(10):1304-1313.

129. Barkley RA, Murphy K, Fischer M: ADHD in Adults: What the Science Says. New York: Guilford Press; 2008.

130. Coghill DR, Rhodes SM, Matthews K: The neuropsychological effects of chronic methylphenidate on drug-naive boys with attention-deficit/ hyperactivity disorder. Biol Psychiatry 2007, 62(9):954-962.

131. Swanson J: Compliance with stimulants for attention-deficit/hyperactivity disorder: issues and approaches for improvement. CNS Drugs 2003, 17(2):117-131.

132. McGough JJ: Attention-deficit/hyperactivity disorder pharmacogenomics. Biol Psychiatry 2005, 57(11):1367-1373.

133. Mick E, McGough JJ, Middleton FA, Neale B, Faraone SV: Genome-wide association study of blood pressure response to methylphenidate treatment of attention-deficit/hyperactivity disorder. Prog Neuropsychopharmacol Biol Psychiatry 2011.

134. Mick E, Neale B, Middleton FA, McGough JJ, Faraone SV: Genome-wide association study of response to methylphenidate in 187 children with attention-deficit/hyperactivity disorder. Am J Med Genet B Neuropsychiatr Genet 2008, 147B(8):1412-1418.

\section{Pre-publication history}

The pre-publication history for this paper can be accessed here: http://www.biomedcentral.com/1741-7015/9/72/prepub

doi:10.1186/1741-7015-9-72

Cite this article as: Antshel et al:: Advances in understanding and treating ADHD. BMC Medicine 2011 9:72.

\section{Submit your next manuscript to BioMed Central and take full advantage of:}

- Convenient online submission

- Thorough peer review

- No space constraints or color figure charges

- Immediate publication on acceptance

- Inclusion in PubMed, CAS, Scopus and Google Scholar

- Research which is freely available for redistribution

Submit your manuscript at www.biomedcentral.com/submit
C Biomed Central 